\title{
Evaluation of a project to enhance knowledge of hereditary diseases and management
}

\author{
Ian R Walpole, Charles Watson, Diane Moore, Jack Goldblatt, Carol Bower
}

Genetic Services of Western Australia, Agnes Walsh House, King Edward Memorial Hospital, 374 Bagot Road, Subiaco, WA 6008, Australia

I R Walpole

J Goldblatt

Faculty of Health and Behavioural Sciences, University of Wollongong, Northfields Avenue, Wollongong, NSW 2522, Australia C Watson

Hereditary Disease Program, Health Department of Western Australia, Grace Vaughan House, 227 Stubbs Terrace, Shenton Park, WA 6008, Australia D Moore

Birth Defects Registry, King Edward Memorial Hospital, 374 Bagot Road, Subiaco, WA 6008, Australia

C Bower

Correspondence to: Dr Walpole.

Received 20 December 1996 Revised version accepted for publication 6 May 1997

\begin{abstract}
During 1992 and 1993, in a designated suburban area of Perth, Western Australia, information on hereditary disease was provided for health professionals and the general community. This information was in the form of posters, pamphlets, postal flyers and return letter cards, a static display, newspaper articles, advertisements and radio broadcasts, and professional seminars. The aim of this project was to evaluate the effectiveness of combined strategies to convey practical information about hereditary disease to the community and health professionals. Multiple measures of response evaluation were used, which included structured questionnaire surveys of health professionals and members of the community before and after the project. In the community surveys, respondents who were female, married, middle aged, and parents, and had a higher level of education or were born in Australia, New Zealand, or the United Kingdom were generally better informed about hereditary diseases. This intervention resulted in only meagre changes in community knowledge about hereditary disease, even though promotional materials were shown to be appropriate. General Practitioners (GPs) and Child Health Nurses (CHNs) were supportive of clinical genetic services and recognised a need for continuation of education in this field.

There is a rapidly increasing need for community and health professional comprehension of the applications of the new genetic technology. This project indicates that routine educational and health promotion strategies will not be enough to achieve desired levels of knowledge and attitude change.

(F Med Genet 1997;34:831-837)
\end{abstract}

Keywords: educational strategies; evaluation; hereditary disease

Developments in molecular genetics have revolutionised the practice of clinical genetics. Where previously at risk families could be offered few options, the advent of new technologies provides more opportunities for choice in the prevention of hereditary disease. ${ }^{12}$ Use of these technologies has been relatively slow and this is in part because of community and professional ignorance. Some authorities believe that a more active approach to the dissemination of genetic knowledge and the promotion of services is now required..$^{38}$

Health professionals have been slow to accept that genetic health issues are a part of total patient care; appropriate genetic information or referral is frequently only provided with reluctance or not considered necessary by a medical professional unless a request is made by the patient. ${ }^{9-12}$ Few couples seek prepregnancy counselling in relation to genetic issues, a situation likely to change if families and people are better informed on inherited matters. ${ }^{3713}$ The message about hereditary diseases and their prevention is a relatively complex one and health professionals must choose between providing very general information or attempting to give specific details about a large number of rare diseases. Eliciting a family history may require a degree of biological and social knowledge that many health professionals and the community do not possess. It is therefore not surprising that recently developed DNA technology for genetic testing is currently underused in the health care system..$^{13-16}$ There is also considerable misinformation about genetic disease in the community, often aggravated by inaccurate media coverage.

If informed debate about genetic testing and the potential uses of available DNA technology is to occur, health professionals and the community need accurate information about hereditary disease on which to base such a debate. A pilot project was undertaken to test whether a relatively simple, low cost approach to health professionals and the community, using pamphlets, posters, postal flyers, newspaper and radio items, and professional seminars, could increase knowledge of hereditary disease in the community. The aims of the study were to develop promotional materials and other interventions relating to hereditary disease; inform health professionals and the community in the target area about hereditary disease, using the interventions developed; provide a genetic outreach clinic in the target area; evaluate attitudes and acceptance of the project by health professionals; and evaluate knowledge about hereditary disease among members of the community following the above interventions.

The outcomes of the project are described with discussion on problems related to attempts at wide scale population education on human genetics and the evaluation of their efficiency. 
Table 1 Materials used in hereditary disease project strategies

\begin{tabular}{|c|c|c|c|}
\hline Materials & Distribution* & Period of exposure & $\begin{array}{l}\text { Piloted/focus } \\
\text { tested }\end{array}$ \\
\hline \multicolumn{4}{|l|}{ (A) Pamphlets } \\
\hline Genetic counselling & GP, CHN, P, S/D & Throughout & No \\
\hline Testing for birth defects in pregnancy & GP, CHN, P & March 93 onwards & Yes \\
\hline Will my baby be born healthy? & GP, CHN, P & November 93 & Yes \\
\hline \multicolumn{4}{|l|}{ Check your family tree worksheet (How to draw a } \\
\hline pedigree) & GP, CHN, S/D, P, L, HF & January 93 , throughout & Yes \\
\hline \multicolumn{4}{|l|}{ Maternal serum screening for neural tube defect and } \\
\hline Down syndrome & GP, CHN, L, P & January 93 onwards & Yes \\
\hline Your genetic counselling appointment & GP, CHN, P & February 93 & - \\
\hline Fact sheet on hereditary diseases & GP, CHN & Throughout & No \\
\hline $\begin{array}{l}\text { What do you know about hereditary disease? (table 2) } \\
\text { (B) Posters }\end{array}$ & $\mathrm{LD}$ & Throughout & Yes \\
\hline Check your family tree & GP, CHN, L, P & January 93 , throughout & Yes \\
\hline Will my baby be born healthy? & GP, CHN, P, L & November 93 & Yes \\
\hline \multicolumn{4}{|l|}{ (C) Project information kits for professionals } \\
\hline Folder with $\log \&$ enquiry details & GP, CHN & & \\
\hline "Facts on hereditary diseases" fact sheet & $\mathrm{M}$ & & \\
\hline \multicolumn{4}{|l|}{$\begin{array}{l}\text { Prenatal diagnosis booklet } \\
\text { Genetic counselling pamphlet }\end{array}$} \\
\hline $\begin{array}{l}\text { Project information leaflet } \\
\text { (D) Newsletter Bimonthly } \times 6 \text { editions }\end{array}$ & & Alternate months & \\
\hline $\begin{array}{l}\text { (D) Newsletter Bimonthly } \times 6 \text { editions } \\
\text { (E) Meetings/seminars }\end{array}$ & GP, CHN & July $92-N o y e m b e r ~ 93$ & - \\
\hline (F) Static display & $\mathrm{SC}, \mathrm{CH}$ & Limited & \\
\hline
\end{tabular}

${ }^{\star}$ General practitioners (GP), child health nurses (CHN), pharmacies (P), static displays (S/D), libraries (L), letter drops (LD), media $(\mathrm{M})$, health fairs $(\mathrm{HF})$, shopping centres $(\mathrm{SC})$, council house $(\mathrm{CH})$.

Methods

This study, called the Hereditary Disease Project, was conducted during 1992 and 1993. The target region comprised five adjacent postcode areas of metropolitan Perth (the capital of Western Australia), with a total population of 51380 .

\section{Interventions}

PROMOTIONAL MATERIALS

Pamphlets (table 1), posters (for example, fig 1), and information kits for health professionals were developed. The latter included an outline of the background and aims of the project, a fact sheet on hereditary disease, a prenatal diagnosis booklet (purchased from the NSW Genetic Education Programme), and a genetic counselling pamphlet. Posters and pamphlets were displayed in participating doctors' surgeries, child health centres, day care centres, kindergartens, and pharmacies. Newsletters were sent at regular intervals to all general practitioners (GPs) in the target area, updating them on the project and including an educational article such as maternal serum screening in each issue.

Static display

A large free standing display was placed in various public locations in the target area over the final three week period of intervention strategies. The display design used a large version of the illustration from the leaflet Will my baby be born healthy? (fig 1), with little text and the project telephone number highly visible.

\section{Newspaper promotion}

The project obtained unpaid coverage of items of human interest in hereditary disease in the local community newspapers during an initial three week period. This was followed by a series of three paid full page advertisements Will my baby be born healthy? (fig 1).

INFORMING HEALTH PROFESSIONALS

There were $45 \mathrm{GPs}$, five child health nurses (CHNs), three social workers (SWs), 26 regional administrative health officers (including a community medical officer), and eight pharmacists practising in the target area during the course of the study.

The Chief Investigator or the Project Officer or both visited 24 GPs representing the majority of practices who had agreed to be interviewed to discuss the project. All practices received the project information kit and were later provided with further educational information for display and patient distribution. Of the 24 GPs visited, 17 were willing to participate in a "sentinel" role by recording all enquiries by their patients about hereditary disease matters as well as those patients whom they saw and who had a hereditary disease.

The Project Officer regularly visited $\mathrm{CHNs}$ and they received the project information kit, posters, and pamphlets, attended special inservice seminars, and were invited to make appropriate genetic referrals through family GPs or directly to the Genetic Outreach Clinics.

Pharmacists were contacted by the Project Officer and provided with posters and pamphlets for display and distribution.

\section{INFORMING THE COMMUNITY}

Direct mail strategies

All households in the target area received a direct letterbox drop during the course of the project. Each letter drop included a leaflet, What do you know about hereditary diseases?! Know your family tree, plus a questionnaire return mail card with two multiple choice questions, one about the meaning of the term "genetic disease" and the other about the chance that a baby born in Western Australia has a birth defect. There were initially five separate mailouts to different subsets of postcodes and a sixth repeat mailout to one subset. Recipients were invited to return the questionnaire card and slightly different formats were used in order to evaluate the response rates to each strategy (table 2). 


\section{Will my baby be born healthy?}

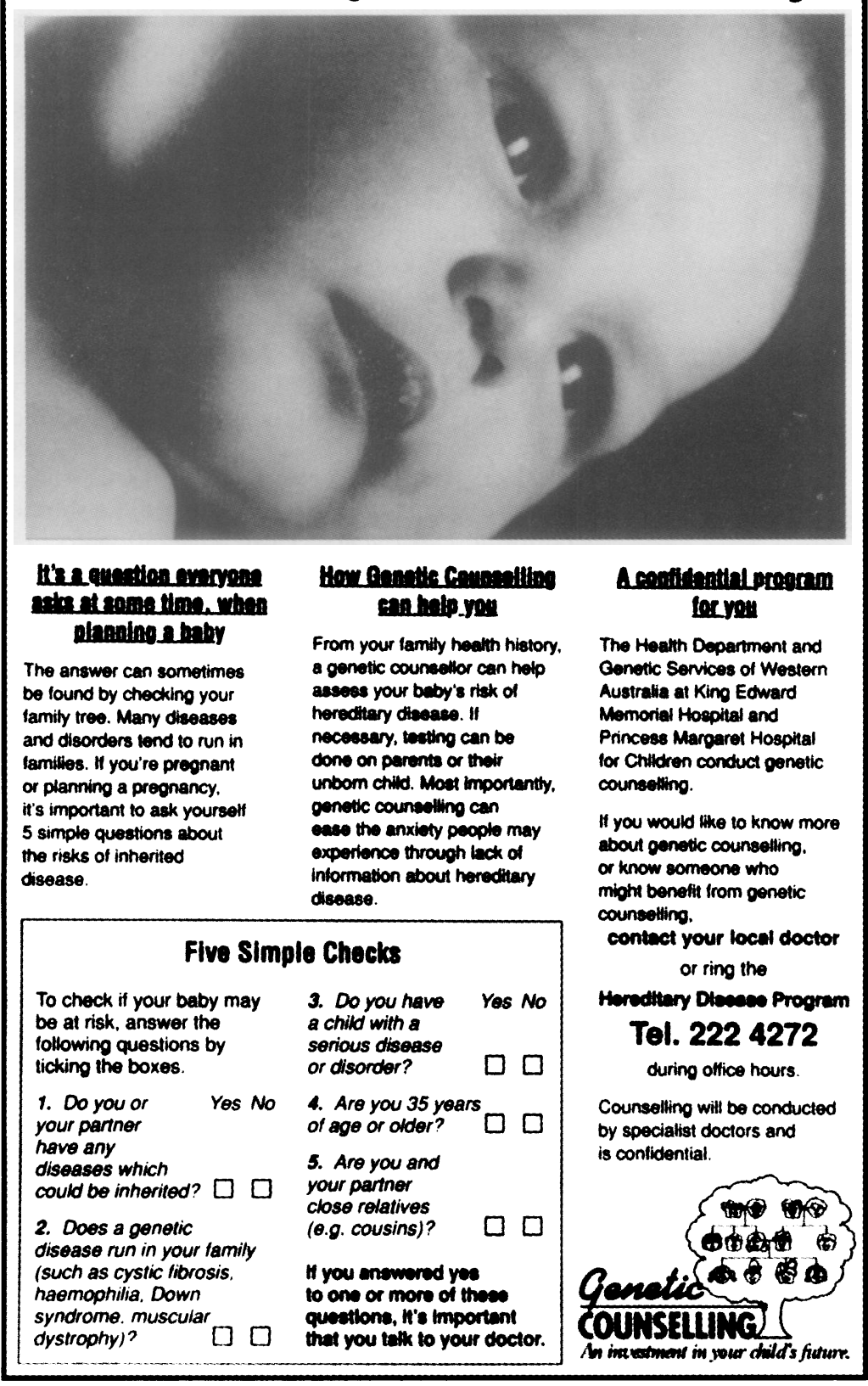

Figure 1 An example of one of the posters.

Incentives to respond were offered. These were the provision of further information and the Genetic counselling pamphlet, a Check your family tree worksheet, and entry into the draw for a pair of jeans.

\section{Phone line}

A dedicated telephone line and answering service was allocated to the Project to receive requests for information.

\section{Genetic outreach clinics}

The purpose of these was to raise community and professional awareness about the project and were established in child health centres during the period of the project. These were intended to provide easy access to specialist genetic information and deal with referrals from local GPs. Referrals from CHNs and selfreferrals were also accepted.
EVALUATION OF HEALTH PROFESSIONALS'

ATTITUDES TO THE PROJECT

The response and participation of GPs in the project was assessed by their overall level of involvement. Responses to the newsletters and replies to questionnaires for feedback on hereditary disease pamphlets, such as that for Maternal serum screening for neural tube defects and Down syndrome, were also recorded. Finally, a self-administered 23 item questionnaire was mailed to general practitioners at the completion of the project to ascertain their attitudes to the relevance of clinical genetics in their practices and the project to which they could respond anonymously.

CHN participation was assessed by willingness to display project posters and pamphlets, rates of referral of individual families to the genetic outreach clinics, and by their attendance at two genetic inservice seminars.

\section{EVALUATION OF COMMUNITY KNOWLEDGE}

The community impact of the project was assessed by two 15 minute shopping centre intercept surveys in which a structured questionnaire was administered by trained interviewers. The first survey was conducted over a two week period in 1992 immediately before any project intervention strategies occurred, and the other was 18 months later at the completion of the project.

Measurement of knowledge was based on questions relating to the definition of genetic disease, how common birth defects are, ability to name a genetic disease, ability to name a prenatal test for genetic disease or birth defects, who might benefit from genetic counselling, and where to obtain information on hereditary disease. Information relating to all these measures was contained in the promotional material distributed as part of the project.

Pre- and post-survey results were compared using chi tests and odds ratios. It was decided a priori to examine the data separately for male and female respondents, as it was felt that the response to the project might differ by gender, and to adjust the odds ratios by several potential confounding variables (age, country of birth, marital status, education of respondent, and whether respondent had children).

Crude and adjusted odds ratios and their $95 \%$ confidence intervals were calculated using multiple logistic regression (Egret 1993).

\section{Results}

ATTITUDES OF HEALTH PROFESSIONALS TO THE PROJECT

At the time of the initial interview, GPs had indicated that they favoured a fortnightly referral genetic outreach clinic. These clinics accepted referrals during the time of the project so that by its completion they were fully booked. Each clinic provided three consultations which were most frequently related to the consultand's own familial risks rather than mere enquiry about general genetic issues. CHNs were relatively more frequently the referring agent than other sources. 


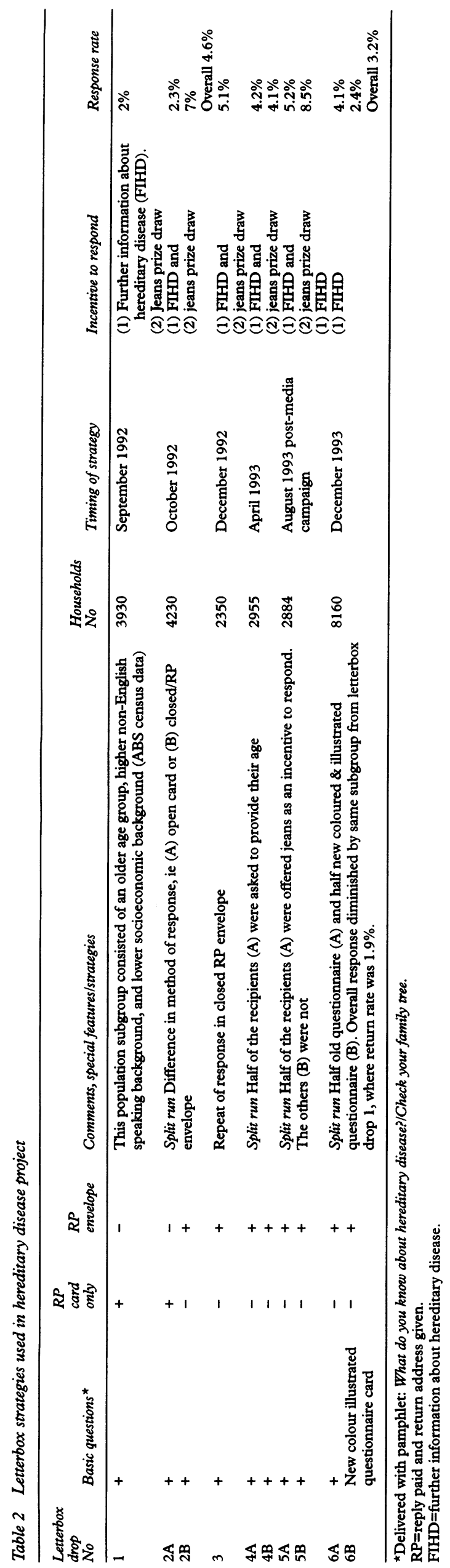

The attitudes of GPs who were interviewed before the launch of the project varied from relatively positive to ambivalence or complete uninterest. At three practices the Chief Investigator and the Project Officer were unable to arrange appointments for interviews.

The 17 sentinel GPs were generally supportive throughout the project, but regular collection of data on practice consultation numbers with hereditary disease was discontinued after six months because of minimal activity.

Of the 45 GPs who were sent the questionnaire at the end of the project, $36(80 \%)$ responded. Eighteen were $<40$ years and 18 were 40 or more years of age. All respondents had been aware of the project and the majority $(24,67 \%)$ thought that the genetic issues raised were important. A greater proportion of GPs aged 40 years and over, compared with those under 40 years, thought that the project should continue ( $<40$ years, $9(50 \%) ; \geqslant 40$ years, 15 $(83 \%)$ ), and that they would continue to display project pamphlets (11 (61\%); 14 $(78 \%))$ and posters in their surgeries $(8(44 \%)$; $13(72 \%))$.

Thirty-three of the 36 GP respondents (92\%) thought the project had professional educational value and that there was a need for further genetic education of GPs. All but one respondent could see a role for GPs in managing patients with hereditary disease, over half had referred patients to genetic outreach clinics, and most felt that the genetic outreach clinics should continue $(<40,9(50 \%) ; \geqslant 40,14$ $(78 \%))$. Only one respondent saw the project as being anxiety provoking and an invasion of privacy.

CHNs in the target area remained key contacts for the duration of the project. They frequently referred patients to genetic clinics either directly or more often through a patient's general practitioner, and they distributed and displayed project information in child health centres as well as contacting community groups, such as play groups and child care organisations.

\section{COMMUNITY RESPONSE TO DIRECT MAIL} STRATEGIES

Return of the mailout questionnaire card varied from $1.9 \%$ to $8.5 \%$. In the split run surveys, the best responses were obtained when a self addressed, reply paid (RP) envelope was provided $(7.0 \%)$, the questionnaire card was plain rather than colourful and illustrated (4.2\%), and when no prize draw incentive was offered $(8.5 \%)$. A request for the age of a respondent did not act as a deterrent (table 2). A population subgroup which received letter drop No 1 and was part of No 6 where a different strategy was used gave the poorest response of the series, $2.0 \%$ and $1.7 \%$. This subgroup contained a higher proportion of older subjects, non-English speaking subjects, and subjects with a low socioeconomic status.

COMMUNITY SURVEYS PRE- AND POST-PROJECT INTERVENTIONS

A total of 250 persons were interviewed before the project interventions were undertaken, and 
Table 3 Pre-and post-surveys: proportion of respondents who chose correct definition of genetic disease by demographic factors

\begin{tabular}{|c|c|c|}
\hline \multirow[b]{2}{*}{ Respondents } & \multicolumn{2}{|c|}{ Proportion choosing correct answer } \\
\hline & Pre $(n=250)$ & Post $(n=248)$ \\
\hline \multicolumn{3}{|l|}{ Age } \\
\hline$<20$ & $11(73.3 \%)$ & $17(85.0 \%)$ \\
\hline $20-29$ & $51(86.4 \%)$ & $52(77.6 \%)$ \\
\hline $30-34$ & $39(92.9 \%)$ & $39(79.6 \%)$ \\
\hline $35-39$ & $29(82.9 \%)$ & $25(100 \%)$ \\
\hline $40-49$ & $41(89.1 \%)$ & $34(94.4 \%)$ \\
\hline $50-59$ & $15(62.5 \%)$ & $25(92.6 \%)$ \\
\hline $60+$ & $19(65.5 \%)$ & $20(83.3 \%)$ \\
\hline \multicolumn{3}{|l|}{ Sex } \\
\hline Male & $94(77.0 \%)$ & $92(87.6 \%)$ \\
\hline Female & $111(86.7 \%)$ & $120(83.0 \%)$ \\
\hline \multicolumn{3}{|c|}{ Highest level of education completed } \\
\hline Primary & $36(61.0 \%)$ & $15(57.7 \%)$ \\
\hline High school & $117(84.8 \%)$ & $141(85.4 \%)$ \\
\hline Technical & $37(97.4 \%)$ & $35(97.2 \%)$ \\
\hline University & $15(100 \%)$ & $21(100 \%)$ \\
\hline \multicolumn{3}{|l|}{ Marital status } \\
\hline Never married & $39(70.9 \%)$ & $61(84.7 \%)$ \\
\hline Married de facto & $132(86.8 \%)$ & $116(87.9 \%)$ \\
\hline Sep/wid/div & $34(79.1 \%)$ & $35(79.5 \%)$ \\
\hline \multicolumn{3}{|l|}{ Country of birth } \\
\hline Australia/New Zealand & $130(82.8 \%)$ & $155(85.6 \%)$ \\
\hline UK & $46(80.7 \%)$ & $36(90.0 \%)$ \\
\hline Europe & $16(69.6 \%)$ & $7(77.8 \%)$ \\
\hline Other & $13(100 \%)$ & $14(77.8 \%)$ \\
\hline \multicolumn{3}{|l|}{ Any children? } \\
\hline Yes & $165(84.6 \%)$ & $138(89.0 \%)$ \\
\hline No & $40(72.7 \%)$ & $74(79.6 \%)$ \\
\hline
\end{tabular}

^Expressed as a percentage of all respondents in that category

†Separated/widowed/divorced (sep/wid/div).

Table 4 Comparisons of knowledge and sources of knowledge of hereditary disease pre and post the hereditary disease project interventions by sex of the respondent

\begin{tabular}{|c|c|c|c|}
\hline & \multicolumn{3}{|c|}{$\begin{array}{l}\text { In response to question: "Can you name any genetic } \\
\text { diseases?" }\end{array}$} \\
\hline & Pre No (\%) & Post No (\%) & $\begin{array}{l}\text { Adjusted } O R^{*} \\
(95 \% \mathrm{CI})\end{array}$ \\
\hline \multicolumn{4}{|c|}{ Nominated a Mendelian disorder } \\
\hline Females & $37(28.9 \%)$ & $39(27.3 \%)$ & $0.80(0.43,1.48)$ \\
\hline Males & $7(5.7 \%)$ & $15(14.3 \%)$ & $2.96(1.04,8.45)$ \\
\hline \multicolumn{4}{|c|}{ Nominated a multifactorial disorder } \\
\hline Females & $62(48.4 \%)$ & $83(58.0 \%)$ & $1.50(0.86,2.59)$ \\
\hline Males & $46(37.7 \%)$ & $49(46.7 \%)$ & $1.55(0.86,2.79)$ \\
\hline \multicolumn{4}{|c|}{ Nominated spina bifida } \\
\hline Females & $6(4.7 \%)$ & $15(10.5 \%)$ & $2.18(0.75,6.29)$ \\
\hline Males & $2(1.6 \%)$ & $3(2.9 \%)$ & $1.65(0.25,10.74)$ \\
\hline \multicolumn{4}{|c|}{ Nominated Down syndrome } \\
\hline Females & $13(10.2 \%)$ & $34(23.8 \%)$ & $2.71(1.26,5.85)$ \\
\hline Males & $5(4.1 \%)$ & $16(15.2 \%)$ & $6.41(1.93,21.31)$ \\
\hline \multicolumn{4}{|c|}{ Nominated a health professional as a source of information } \\
\hline Females & $80(62.5 \%)$ & $115(80.4 \%)$ & $1.71(1.00,2.92)$ \\
\hline Males & $74(60.6 \%)$ & $87(82.8 \%)$ & $3.01(1.63,5.56)$ \\
\hline \multicolumn{4}{|c|}{ Nominated a hospital as a source of information } \\
\hline Females & $33(25.8 \%)$ & $55(38.5 \%)$ & $1.89(1.09,3.27)$ \\
\hline Males & $32(26.2 \%)$ & $29(27.6 \%)$ & $0.94(0.52,1.69)$ \\
\hline \multicolumn{4}{|c|}{ Nominated the Health Department as a source of information } \\
\hline Females & $34(26.6 \%)$ & $44(30.8 \%)$ & $1.25(0.72,2.17)$ \\
\hline Males & $29(23.8 \%)$ & $24(22.9 \%)$ & $0.96(0.51,1.81)$ \\
\hline \multicolumn{4}{|c|}{ Knew about Genetic Counselling Services in WA } \\
\hline Females & $30(23.4 \%)$ & $34(23.8 \%)$ & $1.16(0.63,2.12)$ \\
\hline Males & $13(10.6 \%)$ & $14(13.3 \%)$ & $1.45(0.62,3.38)$ \\
\hline
\end{tabular}

${ }^{\star} \mathrm{OR}$, odds ratio $=$ the odds of outcome after the project divided by the odds of outcome before the project.

$95 \% \mathrm{CI}=95 \%$ confidence intervals.

Odds ratio adjusted for education, age, country of birth, marital status, and whether respondent has any children. second survey had children or had only completed primary education.

In both surveys, respondents less likely to choose the correct definition of genetic disease were those with less education, those who had never married, those born in Europe, and those who had no children. In the first survey but not the second, respondents under 20 and over 50 years of age were also less likely to choose the correct definition (table 3).

In response to the question "Can you name any genetic diseases?", female respondents were more likely than males to offer a valid answer. However, when comparing the preand post-surveys, an increase in knowledge (as assessed by the odds ratio) was seen for both males and females nominating a multifactorial disorder, spina bifida, and Down syndrome. Very few of these differences were statistically significant (table 4).

There was no improvement in knowledge between the two surveys for either men or women about who might benefit from genetic counselling in five of six specified situations (if they already have a child with a serious disorder; when a woman over 35 years of age plans to have a baby; when marrying a close relative; when either parent has a serious disorder which may be passed on to their children; and when a woman has had more than two miscarriages). A three-fold (but statistically non-significant) increase was seen in knowledge about the benefit of genetic counselling if a disorder runs in the family (data not shown).

Both men and women were significantly more likely to nominate a health professional as a source of information about genetic disease after the project than they were before the project. Women, but not men, also nominated hospitals and the Health Department more frequently after the project. Fewer than one in four respondents knew of the existence of the genetic counselling services and there was little increase in this knowledge over the study period for either men or women (table 4).

At the time of the second survey, respondents were shown the pamphlet and posters produced for the project and asked if they had seen them before. A total of $8.3 \%$ of males and $16.9 \%$ of females had seen the pamphlets, and $10.5 \%$ of males and $37.8 \%$ of females had seen the most widely distributed of the posters. More women $(29.4 \%)$ than men $(16.2 \%)$ reported seeing the static display. Only $14.3 \%$ of males and $20.9 \%$ of females recalled receiving anything through the mail about hereditary disease. People who had seen the pamphlets or the poster were about three times more likely to have chosen the correct definition of a genetic disease.

\section{Discussion}

In this pilot Hereditary Disease Project promotional materials were developed, information was provided to health professionals and the community, and a genetic outreach clinic was established. In the community surveys before and after the promotional events, respondents who were married, middle aged, had children, had a higher level of education, or were born in dom and Europe in the second survey (and correspondingly more born in Australia and New Zealand). Fewer respondents at the 
Australia, New Zealand, or the United Kingdom were more likely to choose the correct definition of genetic disease. Women also tended to be better informed about hereditary disease. However, there were few significant improvements in knowledge after the interventions among male or female respondents and the overall level of knowledge was not high. Health professionals were commonly cited as a source of information about hereditary disease, underscoring the importance of GPs having the knowledge of either the condition the patient may be enquiring about or the knowledge of where such information can be provided.

There are several possible reasons for the lack of improvement in awareness of hereditary disease as a result of this project. Firstly, the time frame of the project was short (18 months) and because of the complexity of the hereditary disease messages, they may be less easy to impart quickly and in simple form, both to the public and to health professionals. A further explanation is that the materials may not have been distributed sufficiently widely. A third or fewer of the people surveyed recalled seeing the pamphlets, posters, or the static display, and an even smaller proportion could recall receiving anything through the mail about hereditary disease. This was despite distributing the materials in many locations where women and children congregate, along with health centres, pharmacies, and general practices, and the fact that all households in the target area had been sent at least one project letter. It may be that a more diverse range of materials with messages of greater relevance to the informal or lay views of the community may have been more successful in communicating hereditary messages. ${ }^{16-19}$

There is evidence that some genetic information is of low interest to recipients except when they are pregnant or actually planning a family. ${ }^{15} 20$ There is greater interest in information about particular hereditary diseases where that level of knowledge within the community is greater or if the recipient has heard or knows of a person or family member with the condition. $^{2021}$ The project may not have accounted for important perceptive and cultural factors which strongly influence the recognition of the intended genetic message. Lay belief has been identified to be of importance to people and families in their interpretation of hereditary principles. ${ }^{16-19}$

GPs, who were generally supportive of the project, require further support and encouragement in genetic education and indicated their desire for further practical information, such as ways of identifying patients who might benefit from genetic counselling. At least a third of GPs have indicated in other studies that they see a role for themselves in community health education, which is in keeping with what is expected of them by many in the community. ${ }^{22} \mathrm{CHNs}$ were enthusiastic in their support of the project, referring patients in appropriate circumstances. Special event Genetic Education Weeks for health professionals have received acceptance and favourable re- sponses, but there has been no objective evaluation over time to assess their effect. ${ }^{8}$ In this project, many of the materials used in letterdrop pamphlets appeared to draw a satisfactory response rate, but in the shorter term did not raise the awareness of hereditary diseases. Future programmes could consider higher profile media channels, such as television. A greater precision in targeting of information (for example, to females of reproductive age) may be advantageous but a possible weakness inherent in this approach is that the older generation may be those who provide the family with information on this subject. ${ }^{16} 18$

The multitude of hereditary diseases, many of them rare, makes it impossible for a programme to address each individually. Our general message, such as Will my baby be born healthy?, was well received by focus groups and by interviewees, but alone did not register greatly in the community awareness of hereditary disease.

We believe that the potential impact of medical genetics in community health care is so great that there is a need to conduct further studies implementing some of the suggested changes in approach. A future programme to promote community awareness of hereditary disease should be multifaceted and long lasting. Ingrained misconceptions about inheritance can be best addressed by education, firstly at upper school levels. Some of the more common and significant misconceptions, like those referring to the risks of autosomal recessive inheritance, require the development of promotional materials which directly address and simply describe the mechanisms. Focus groups were used to develop materials for this project, but greater cognisance of informal or lay beliefs will demand further research and consumer involvement in the development of educational programmes. ${ }^{18} 1923-25$

The rapid pace of new discoveries in the field of molecular and clinical genetics has revolutionised the management of at risk families. However, formal programmes to transmit appropriate knowledge to both the public and health professionals have been conspicuously absent. The optimal development of education, counselling, and support strategies requires much research, new approaches, and should lead to people, families, and health professionals becoming more aware of hereditary disease risks and choices in terms of management and reproduction options which were not previously available.

The authors would like to thank Elizabeth Reeson and Terri Cutmore for valuable research assistance and support, and Yve Gaunt and Kate Wang for typing and layout advice. The work was supported by the Commonwealth Department of Health and Family Services Research and Development Grant funding.

1 Modell B, Modell M. Towards a healthy baby: congenital disorders and the new genetics in primary health care. Oxford: Oxford University Press, 1992.

2 Czeizel AE, Intody $\mathrm{Z}$, Model $\mathrm{B}$. What proportion of congenital abnormalities can be prevented? BMf 1993; 306:499-503. 
3 Modell B. Community screening for cystic fibrosis. $7 \mathrm{Med}$ Genet 1990;27:475-9.

4 Graver KI, Le Chien K. Geneticist's responsibility to other health care professionals and to lay public. Am f Hum Genet 1992;51:922-3.

5 Danks DM. Whither genetic services? Med F Aust 1993;159:

6 Wilfond BS, Nolan K. National policy development for the clinical application of genetic diagnostic technologies. fAMA 1993;270:2948-54

7 Clayton EW, Hannig VL, Pfotenhaner JP, et al. Teaching about cystic fibrosis carrier screening by using written an video information. Am $\mathcal{F}$ Hum Genet 1995;57:171-81.

8 Borgaonkar DS. Genetics week in Delaware: a new concep in genetics education for health-care providers in the community. Am ₹ Hum Genet 1992;51:220-1.

9 Weitz R. Barriers to acceptance of genetic counselling among primary care physicians. Soc Biol 1984;26:189-97.

10 Faden RR, Tambor ES, Chase GA, et al. Attitudes of physicians and genetic professionals toward CF carrier screening. $A m \mathcal{F}$ Med Genet 1994; 50:1-11.

11 Rowley PT, Loader S, Levenkron S, et al. Cystic fibrosis screening: knowledge and attitudes of prenatal care providers. Am F Prev Med 1993;9:261-6.

12 Naylor EW. Genetic screening and genetic counselling: knowledge, attitudes, and practices in two groups of family knowledge, attitudes, and practices in two groups
planning professionals. Soc Biol 1975;22:304-14.

13 Harris R, Elles R, Craufurd D, et al. Molecular genetics in the national health service in Britain. $₹$ Med Genet 1989;26. 219-25.

14 Harper P. Genetics and public health. BMF 1992;304:721.

15 Welkenhuysen M, Evers-Kiebooms G, Decruyenaere M, al. Adolescents' attitudes towards carrier testing for cystic fibrosis and its relative stability over time. Eur $\mathcal{F}$ Hum Gene 1996;4:52-62.
16 Ponder M, Lee J, Green J, Richards M. Family history and perceived vulnerability to common diseases: a study of
young people and their parents. $\mathcal{F}$ Med Genet 1996;33:48592.

17 Neidhardt F. The public as a communication system. Public Understanding of Science 1993;2:339-50.

18 Richards $M$, Ponder $M$. Lay understanding of genetics: a test of a hypothesis. $f$ Med Genet 1996;33:1032-6.

19 Durant J, Hansen A, Bauer M. Public understanding of the new genetics. In: Marteau T, Richards MPM, eds. The troubled helix: social and psychological implications of the new human genetics. Cambridge: Cambridge University Press, human.

20 Clayton EW, Hannig VL, Pfotenhauer JP, et al. Lack of interest by non-pregnant couples in population-based cystic fibrosis carrier screening. Am 7 Hum Genet 1996;58: 617-27.

21 Scriver CR, Bardanis M, Cartier $L$, et al. $\beta$ thalassaemia disease prevention: genetic medicine applied. Am $\mathfrak{f}$ Hum Genet 1984;36:1024-38.

22 Girgis A, Sanson-Fisher R. Community based health education: general practitioners' perceptions of their role and willingness to participate. Aust NZ $\mathcal{F}$ Pub Health 1996; 20:381-5.

23 Graham JM Jr, Rotter I, Riccardi VM, et al. Report of the task force on teaching human genetics in North American medical schools. Am $¥$ Hum Genet 1989;44:161-5.

24 A report of the Royal College of Physicians prenatal diagnosis and genetic screening: community and service implications. London. The Royal College of Physicians, Septemtions. Lond 1989 .

25 Myers MF, Bernhardt BA, Tambor ES, et al. Involving consumers in the development of an Education Program for cystic fibrosis carrier screening. Am $\mathcal{F}$ Hum Genet 1994;54 719-26. 